Olawale, O.S. et al. (2017). Relationship between Cardiorespiratory Fitness and Anthropometric Variables among school-going adolescents in Nigeria.

The Anthropologist, 29(1): 65-72.

http://dx.doi.org/10.1080/09720073.2017.1351514

\title{
Relationship between Cardiorespiratory Fitness and Anthropometric Variables among school-going adolescents in Nigeria
}

\author{
Onagbiye S. Olawale, Mulubwa Mwila, Young M.E. Marie and Toriola A. Lamina
}

\begin{abstract}
The increase in physical activity (PA) levels has been known to be associated with improved cardiorespiratory fitness status which helps in reducing the risk factors of non-communicable disease. However, the interaction between cardiorespiratory fitness and anthropometric variables remains unclear and needs further investigation. This study assessed the relationship between cardiorespiratory fitness and anthropometric variables among school-going adolescents in Nigeria. Two hundred and fifty apparently healthy participants ranging from 12 to 20 years of age, who were randomly selected, participated in this study. Height, body weight, and body mass index (BMI) were measured. Cooper's 12 minutes run/walk test was conducted to assess cardiorespiratory fitness (estimated by maximal oxygen uptake: VO2max). There was a significant correlation betweenVO2max and BMI. In the regression model, weight, height, gender, and BMI accounted for ninety-five percent of the total variance in the participants' cardiorespiratory fitness. Body weight, height, gender, and BMI were significant predictors of cardiorespiratory fitness in the school-going Nigerian adolescents.
\end{abstract}

\section{Introduction}

The increase in physical activity (PA) levels has been associated with improved cardiorespiratory status which helps in reducing the risk factors of non-communicable diseases (NCDs). Cardiorespiratory fitness (CRF) is the ability to perform day-to-day bodily work without hurting the psychosocial health (Victo et al. 2017). Inadequate or low aerobic fitness is positively correlated with excessive body weight and inactive lifestyle (Victo et al. 2017). A reduction in the mean values of cardiorespiratory fitness among youngsters from a number of nations has been established, including Brazil and Britain (Victo et al. 2017). Healthwise, the insufficient levels of aerobic fitness of youths is linked to the increase in premature mortality risk caused mostly by cardiovascular diseases (De Araujo et al. 2015). Cardiorespiratory fitness could be seen as an autonomous element of healthiness throughout the lifecycle, and is known to be correlated with improvements in both physiological and cognitive functioning (Esmaeilzadeh et al. 2013).

A number of studies (Bray et al. 2009; Esmaeilzadeh et al. 2013) have suggested that although cardiorespiratory fitness may be genetic, it can also be affected by environmental factors. The suggested environmental factors were PAlevels, socio-economic status, prolonged television viewing and anthropometric factors (Esmaeilzadeh et al. 2013). Obesity has been understood to be associated with the increase in blood pressure level, type 2 diabetes mellitus, hyperlipidaemia, and untimely death (Gonçalves et al. 2015). Anthropometric parameters such 
as body mass index (BMI) and waist circumference have been considered to be strong indicators of total fat and central obesity in that order (Camhi and Katzmaryzk 2010; Goncalves et al. 2015).

In spite of the considerable body of evidence in the literature on risk factors of cardiovascular disease among adolescents (Esmaeilzadeh et al. 2013; De Araujo et al. 2015; Gonçalves et al. 2015), relatively few studies have examined the relationships between cardiorespiratory fitness and anthropometric variables among school-going adolescents in Nigeria. Considering that the CRF testing and anthropometric measurements are foundational phase for lifestyle-changing interventions (Andreasi et al. 2010), understanding the relationships and predictor variables may inform quick and early intervention in combating the growing risk factors of non-communicable diseases. Therefore, the main purpose of this study was to determine the relationship between CRF and selected anthropometric variables among school-going adolescents in Nigeria.

\section{Methodology \\ Research Design}

A descriptive survey design was used to examine the relationship between CRF and selected anthropometric variables among school-going adolescents in Nigeria. A descriptive design is selected because of its high degree of representativeness and the ease with which a researcher could obtain participants' data (Polit and Beck 2004).

\section{Participants}

The population for this study included all students at 8 public senior secondary schools in Ife Central Local Government Area of Osun State, Nigeria. Five secondary schools were randomly selected from eight public senior secondary schools available in the area. The stratified random sampling method was used to select fifty students from each school comprising 25 males and 25 females. In total 250 students (125 males, 125 females), ranging from 12 to 20 years of age (mean \pm SD: $15.2 \pm 1.92$ years) participated in this study. All the participants and their parents gave written informed consent before they were allowed to participate in the study.

\section{Anthropometric Measurements}

The participants' height and body weight were measured using the standard procedures described recommended by the International Society for the Advancement of Kianthropometry (ISAK) (Marfell-Jones et al. 2006). Body mass index (BMI) was calculated as body mass/(stature $)^{2}\left(\mathrm{~kg} / \mathrm{m}^{2}\right)$. It is a simple ratio of weight and height that reflects body composition, especially in the diagnosis of obesity.

\section{Measurement of Aerobic Fitness: Cooper 12- Minute Run/Walk Test}

Participants' CRF was assessed using Cooper's 12 minutes run/walk test. This is a wellknown maximal test of aerobic fitness, in which the participants try to run and cover as much distance as they can in 12 minutes. This test can be modified to be suitable for most populations as it is a simple test of aerobic fitness that requires less expensive equipment (Cooper 1968). The Cooper's test is a genuine and dependable procedure for which a great group of participants can be assessed at once with a correlation of 0.90 between $\mathrm{VO}$ and the distance covered in a 12 minutes' walk/run (Cooper 1968). In addition, the consistency of the cooper test relied on preparation, pacing strategies and the level of motivation of the participants. 


\section{Measurements Procedure}

Preceding the data collection, permission to carry out the measurements was obtained from the Ife Central Local Government Education Authority, Ile Ife, Nigeria, as well as the Postgraduate Ethics Committee of the Obafemi Awolowo University, Ile-Ife, Nigeria. In addition, permission was also sought for and clearance was received from the school heads, that is, principal and game master of each school. The participating schools were briefed about the purpose of the study, and the informed consent forms were signed by the school authorities, the students and their parents. The physical and physiological variables were measured in the following order: anthropometry, and physical fitness. All anthropometric sites were measured thrice and the average was calculated according to standard procedures. The Cooper's 12 minutes run/walk test was conducted at the Obafemi Awolowo University (OAU) sport complex arena to assess CRF as estimated by maximal oxygen uptake $\left(\mathrm{VO}_{2 m a x}\right)$.

Objects were placed at fixed intervals around the 40om running track to help in the assessment of completed distances. The participants were instructed to warm-up for about 10 minutes and stretch afterwards before the actual test commenced. The researchers also organized the participants in batches to avoid rowdiness and to allow free movement. Participants ran/ walked constantly for 12 minutes and the distances covered were documented. Walking was permitted, nevertheless the participants were stimulated to drive themselves as hard as they can. Research assistants were employed to monitor, record laps and distances covered by participants. Before the test commenced, participants were told to stand at the starting point and start running immediately after the whistle had been blown. The test administrator called out the elapsed time on each occasion that they passed the starting point. The research assistants kept track of the number of laps completed. At the end of 12 minutes, a whistle was blown to stop the participants, who also maintained their location on the track until the administrator or the research assistants has recorded the ending positions. Thereafter, participants were allowed to walk back and forth to the outside of the track in order to cool down.

\section{Equation Used for Computation}

The BMI (Quetelet's Index) of each participant was computed using Lohman's (1987) equation: Weight (Kg) / [Height (m) ${ }^{2}$. Cooper 12-minute run/walk performance of each participant was computed using Cooper's (1968) equation: 0.0225 multiplied by meters covered -11.3.

\section{Validity and Reliability of the Instrument}

The validity and reliability of the data collection instrument were ascertained before data collection. Because a digital home bathroom weighing scale $(r=0.968, p<0.001)$ was used to assess the participants body weight, the scale was validated by measuring sets of known weight on the scale. Pearson moment correlation was used to find the relationship between the recorded weight value indicated on the weighing scale and the known weight value. Furthermore, height was measured with an improvised wall ruler $(r=0.875$, $\mathrm{p}<0.001)$ which was correlated with a standard ruler. In addition, the bathroom weighing scale was reset to zero before each use. Yorkin et al. (2013) have reported that a digital home bathroom weighing scale offers adequately precise and reliable weights for public health research. Prompt reset to zero scale before each use could promote precision of weight measurements (Yorkin et al. 2013). 


\section{Data Analyses}

Independent samples t-test was performed to examine if any significant differences existed between the variables. Bivariate association between the CFR and anthropometric measurements were determined with Pearson's product correlation coefficient separately for boys and girls alone, whose data were subsequently combined for further analysis. The correlations were interpreted using the categorization of Dancey and Reidy (2004) of which the $r$-value of \pm 1 is taken as a perfect association, $r$-values between \pm 0.7 to \pm 0.9 indicating a strong relationship, $r$-values in the range \pm 0.4 to \pm 0.6 are classified as moderate relationships, $r$-values between \pm 0.1 to \pm 0.3 reflect weak associations and the $r$-value of 0 denotes that there is no relationship between the variables investigated. Multiple linear regression modeling was used to determine the relative influence of variables measured (age, body weight, height, gender, and BMI). Alpha level was set at 0.05 and data were analysed by using the Statistical Package for Social Sciences (SPSS) version 23.0 for Windows (IBM SPSS Inc., Chicago, IL).

\section{Results}

A total of 250 participants, comprising 125 (50\%) adolescent boys and 125 (50\%) girls

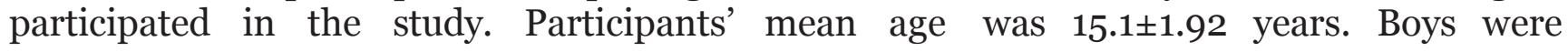
insignificantly taller and older while girls $\left(46.9 \pm 8.05 \mathrm{~kg} / \mathrm{m}^{2}\right)$ were non-significantly heavier than the boys $\left(44.7 \pm 10.3 \mathrm{~kg} / \mathrm{m}^{2}\right)$. Gender comparisons of these parameters showed that there were significant differences in the participants' BMI and CFR $(\leq 0.05)$. In terms of BMI girls $\left(19.9 \pm 2.71 \mathrm{~kg} / \mathrm{m}^{2}\right)$ had relatively higher mean value, while boys (VO2max: $44.1 \pm 9.17 \mathrm{ml} / \mathrm{kg} / \mathrm{min})$ were fitter than the girls $(32.5 \pm 6.95 \mathrm{ml} / \mathrm{kg} / \mathrm{min})$. Furthermore, there was no significant difference in age, height, and body weight of participants ( $>0.05$ ) (Table 1). The bivariate correlation among the boys revealed that there was no relationship between $\mathrm{VO}_{2 \max }$ and age $(\mathrm{r}=-0.034, \mathrm{p}>0.05), \mathrm{VO}_{2} \max$ and body weight $(\mathrm{r}=0.085, \mathrm{p}>$ 0.05), VO2max and BMI $(r=-0.009, p>0.05)$, while a non-significant relationship was found between $\mathrm{VO}_{2}$ max and height $(\mathrm{r}=0.142, \mathrm{p}>0.05)$ (Table 2). In girls, there were little or no relationships between $\mathrm{VO}_{2}$ max and age $(\mathrm{r}=0.030, \mathrm{p}>0.05), \mathrm{VO}_{2}$ max and body weight $(\mathrm{r}=$ -0.060, p >0.05), VO2max and height (-0.033, p >0.05), as well as VO2max and BMI ( $\mathrm{r}=-$ $0.056, \mathrm{p}>0.05)$ (Table 3$)$.

The correlation matrix of the relationship between CRF and selected anthropometric variables in both boys and girls revealed that there were no relationships between VO2max and age $(\mathrm{r}=0.012, \mathrm{p}>0.05)$, VO2max and weight $(\mathrm{r}=-0.044, \mathrm{p}>0.05)$, and $\mathrm{VO}_{2}$ max and height (0.097, $\mathrm{p}>0.05$ ). On the other hand, there was an inverse significant correlation between $\mathrm{VO}_{2 m a x}$ and BMI $(\mathrm{r}=-0.169, \mathrm{p}<0.01)$ (Table 4). The results of the multiple linear regression analysis performed for all participants to predict $\mathrm{VO}_{2 \max }$ based on their body weight, height, gender, and BMI are provided in Table 5. The results showed that every kilogram change in body weight leads to a higher significant decrease in VO2max by $0.5 \mathrm{ml} / \mathrm{kg} / \mathrm{min}$. 
Table 1: Physical characteristics of the participants (Mean \pm SD) $(n=250)$

\begin{tabular}{llccr}
\hline Variables & Boys $(n=125)$ & Girls $(n=125)$ & Total $(n=250)$ & $p$-value \\
\hline Age $(\mathrm{yrs})$ & $15.2 \pm 1.97$ & $15.1 \pm 1.87$ & $15.1 \pm 1.92$ & 0.62 \\
Height $(\mathrm{m})$ & $1.54 \pm 0.11$ & $1.53 \pm 0.06$ & $1.53 \pm 0.94$ & 0.53 \\
Weight $(\mathrm{kg})$ & $44.7 \pm 10.3$ & $46.9 \pm 8.05$ & $45.8 \pm 9.32$ & 0.57 \\
BMI $\left(\mathrm{kg} / \mathrm{m}^{2}\right)$ & $18.6 \pm 2.53$ & $19.9 \pm 2.71$ & $19.3 \pm 2.71$ & $0.00^{*}$ \\
PVO $_{2 \max }(\mathrm{ml} / \mathrm{kg} / \mathrm{min})$ & $44.1 \pm 9.17$ & $32.5 \pm 6.95$ & $38.3 \pm 9.98$ & $0.00^{*}$
\end{tabular}

"Significant $\mathrm{p}<0.05 ; \mathrm{PVO}_{2 \max } ;$ predicted maximum oxygen consumption

BMI; body mass index, Yrs.; years, $\mathrm{kg}$; kilogram, $\mathrm{m}$; meter, $\mathrm{kg} / \mathrm{m}^{2}$; kilogram per meter square, $\mathrm{ml} / \mathrm{kg} / \mathrm{min}$; millilitre per kilogram per minutes, $\mathrm{n}$; number

Table 2: Correlation matrix showing the relationship between cardiorespiratory fitness and selected anthropometric variables in boys $(n=125)$

\begin{tabular}{|c|c|c|c|c|c|}
\hline Variables & $\operatorname{Age}\left(Y_{r}\right)$ & Weight (kg) & Height $(m)$ & $B M I\left(\mathrm{~kg} / \mathrm{m}^{2}\right)$ & $\mathrm{PVO}_{2 \max }(\mathrm{ml} / \mathrm{kg} / \mathrm{min})$ \\
\hline Age (yrs) & 1.00 & & & & \\
\hline Weight (kg) & $0.243^{* *}$ & 1.00 & & & \\
\hline Height (m) & $0.177^{\circ}$ & $0.856^{\circ *}$ & 1.00 & & \\
\hline BMI $\left(\mathrm{kg} / \mathrm{m}^{2}\right)$ & $0.280^{* *}$ & $0.783^{* *}$ & $0.368^{* *}$ & 1.00 & \\
\hline $\mathrm{PVO}_{2 \max }(\mathrm{ml} / \mathrm{kg} / \mathrm{min})$ & -0.034 & 0.085 & 0.142 & -0.009 & 1.00 \\
\hline
\end{tabular}

"Correlation is significant at the 0.01 level (2-tailed)

* Correlation is significant at the 0.05 level (2-tailed)

$\mathrm{PVO}_{2 \max }$; predicted maximum oxygen consumption

BMI; body mass index, Yrs.; years, $\mathrm{kg}$; kilogram, $\mathrm{m}$; meter, $\mathrm{kg} / \mathrm{m}^{2}$; kilogram per meter square, $\mathrm{ml} / \mathrm{kg} / \mathrm{min}$; millilitre per kilogram per minutes

Table 3: Correlation matrix showing the relationship between cardiorespiratory fitness and selected anthropometric variables in girls $(n=125)$

\begin{tabular}{|c|c|c|c|c|c|}
\hline Variables & Age (Yr) & Weight (kg) & Height (m) & $B M I\left(\mathrm{~kg} / \mathrm{m}^{2}\right)$ & $\mathrm{PVO}^{2} \max (\mathrm{ml} / \mathrm{kg} / \mathrm{min})$ \\
\hline Age (yrs) & 1.00 & & & & \\
\hline Weight (kg) & $0.303^{* *}$ & 1.00 & & & \\
\hline Height (m) & 0.163 & $0.624^{* *}$ & 1.00 & & \\
\hline BMI $\left(\mathrm{kg} / \mathrm{m}^{2}\right)$ & $0.296^{* *}$ & $0.881^{* *}$ & $0.198^{\circ}$ & 1.00 & \\
\hline $\mathrm{PVO}_{2} \max (\mathrm{ml} / \mathrm{kg} / \mathrm{min})$ & 0.030 & -0.060 & -0.033 & -0.056 & 1.00 \\
\hline
\end{tabular}

${ }^{*}$ Correlation is significant at the 0.01 level (2-tailed)

* Correlation is significant at the 0.05 level (2-tailed)

$\mathrm{PVO}_{2 \max }$; predicted maximum oxygen consumption

BMI; body mass index, Yrs.; years, $\mathrm{kg}$; kilogram, m; meter, $\mathrm{kg} / \mathrm{m}^{2}$; kilogram per meter square, $\mathrm{ml} / \mathrm{kg} / \mathrm{min}$; millilitre per kilogram per minutes

Table 4: Correlation matrix showing the relationship between cardiorespiratory fitness and selected anthropometric variables in both boys and girls $(n=250)$

\begin{tabular}{llllc}
\hline Variables & Age $(\mathrm{Yr})$ & Weight $(\mathrm{kg})$ & Height $(\mathrm{m})$ & BMI $\left(\mathrm{kg} / \mathrm{m}^{2}\right) \quad \mathrm{PVO} \mathrm{O}_{2 \max }(\mathrm{ml} / \mathrm{kg} / \mathrm{min})$ \\
\hline Age $(\mathrm{yrs})$ & 1.00 & & & \\
Weight $(\mathrm{kg})$ & $0.261^{* *}$ & 1.00 & 1.00 & \\
Height $(\mathrm{m})$ & $0.167^{* *}$ & $0.766^{* *}$ & $0.270^{* *}$ & 1.00 \\
BMI $\left(\mathrm{kg} / \mathrm{m}^{2}\right)$ & $0.271^{* *}$ & $0.816^{* *}$ & 0.097 & $-0.169^{* *}$ \\
PVO $_{2 \max }(\mathrm{ml} / \mathrm{kg} / \mathrm{min})$ & 0.012 & -0.044 & 1.00 \\
\hline
\end{tabular}

* Correlation is significant at the 0.01 level (2-tailed).

$\mathrm{PVO}_{2} \max ;$ predicted maximum oxygen consumption

BMI; body mass index, Yrs.; years, $\mathrm{kg}$; kilogram, $\mathrm{m}$; meter, $\mathrm{kg} / \mathrm{m}^{2}$; kilogram per meter square, $\mathrm{ml} / \mathrm{kg} / \mathrm{min}$; millilitre per kilogram per minutes 
Table 5: Multiple linear regression analysis to predict cardiorespiratory fitness and selected anthropometric variables

\begin{tabular}{lcr}
\hline Variables & Co-efficient $(\hat{a})$ & $P$-value \\
\hline Weight $(\mathrm{kg})$ & -0.498 & $<0.001$ \\
Height $(\mathrm{m})$ & 39.012 & $<0.001$ \\
Gender & -11.438 & $<0.001$ \\
BMI $\left(\mathrm{kg} / \mathrm{m}^{2}\right)$ & 0.954 & 0.001 \\
\hline
\end{tabular}

$\mathrm{R}$ square $=0.959 ;$ adjusted $\mathrm{R}$ square $=0.958$

$\mathrm{P}<0.05$

This means that the higher the body weight, the lower the $\mathrm{VO}_{2}$ max. Also, every centimetre change in height leads to higher significant increase in $\mathrm{VO}_{2}$ max by $39 \mathrm{ml} / \mathrm{kg} / \mathrm{min}$. This means that the more increase in height, the higher the $\mathrm{VO}_{2}$ max. Furthermore, the results showed that female gender is associated with higher significant reduction in $\mathrm{VO}_{2}$ max by $11.4 \mathrm{ml} / \mathrm{kg} / \mathrm{min}$ as compared to male gender (where gender is coded as $1=$ male and $2=$ female). In contrast, every kilogram per meter square $\left(\mathrm{kg} / \mathrm{m}^{2}\right)$ change in BMI is associated with a higher significant increase in $\mathrm{VO}_{2} \mathrm{max}$ by $0.9 \mathrm{ml} / \mathrm{kg} / \mathrm{min}$. The generalised equation used to predict $\mathrm{VO}_{2} \max$ from weight, height, gender, and $\mathrm{BMI}$ was: Predicted $\mathrm{VO}_{2}$ max $=39.012$ (height) +0.945 (BMI) -11.438 (gender: $1=$ men, $2=$ women) -0.498 (weight) obtained from coefficients table. The variable significantly predicted $\mathrm{VO}_{2 \max } \mathrm{F}(4,246)=1421.123, p<$ 0.001, $R^{2}=0.959$ at $p \leq 0.05$. Therefore, body weight, height, gender, and BMI were significant predictors of $\mathrm{VO}_{2}$ max.

\section{Discussion}

The primary purpose of this study was to determine if any relationship existed between the cardiorespiratory fitness and selected anthropometric variables among school-going adolescents in IIe-Ife, Nigeria. The physical characteristics of the participants of this study showed that the mean BMI was normal for both the school boys and girls as proposed by the World Health Organization Expert Consultation (WHO 2004). The major findings of this study were that the mean value for $\mathrm{VO}_{2}$ max was higher in boys than girls. These findings are consistent with those of several previous studies (Ostojic et al. 2011; Heroux et al. 2013; De Araujo et al. 2015; Demirkan et al. 2016; Tanha et al. 2016) which found a higher $\mathrm{VO}_{2}$ max mean value in boys compared to girls. The most important factor that may contribute to superior $\mathrm{VO}_{2}$ max values are lean body mass, maximum heart rate, and gender (Demirkan et al. 2016). Gender wise, it has been reported that during puberty, $\mathrm{VO}_{2}$ max in girls increases slowly compared to boys of the same age (Woll et al. 2011; Demirkan et al. 2016). Therefore, physiological changes and differences at this crucial time of sexual maturation among genders might influence CRF (Demirkan et al. 2016). The results of this study also showed that the Nigerian girls had a significantly higher BMI than the boys. Similar findings have been reported in studies conducted by Ostojic et al. (2011), Monyeki et al. (2012), Minasian et al. (2014), De Araujo et al. (2015) and Tanha et al. (2016) which found a higher BMI in girls compared to boys of the same age. This finding can be explained in the light of rapid changes in body composition during sexual maturity often characterised by increased fat mass for girls (Pate et al. 2006; De Araujo et al. 2015). At this 
stage, the $\mathrm{VO}_{2} \max$ is inversely related to BMI coupled with other serum lipid factors (Lamonte et al. 2005). Regardless of the observed gender differences observed in the present study, it should be noted that the participants' BMI values were within the normal range proposed by the World Health Organisation (WHO).

The bivariate correlation analysis performed to examine whether any relationship existed between CRF and selected anthropometric variables among the students revealed that there was no relationship between the $\mathrm{VO}_{2}$ max and the participants' age. Anderssen et al. (2007) observed the relationship between aerobic fitness and CVD risk in randomly selected 2845 youth, aged 9 or 15 years from three European countries (Portugal - n= 944, Denmark $\mathrm{n}=849$, and Estonia $-\mathrm{n}=1052$ ), and found that though cardiorespiratory fitness was strongly associated with the CVD risk factors in youth, but it was independent of country, age, and gender.

Furthermore, there were no relationships between the $\mathrm{VO}_{2}$ max and body mass, and $\mathrm{VO}_{2}$ max and height of the participants in our study. This result contrasts with those of Rutenfranz et al. (1990) and Chatterjee et al. (2006) who found an association between the body height and $\mathrm{VO}_{2}$ max of 129 children aged 8-20 years. In another study conducted in Kolkata, India which examined the prediction models for maximal oxygen uptake from age, body mass and body surface area (BSA) in young sedentary sample, aged between 20 and 24 years (males: $n=40$; females: $n=40$ ) revealed that there was a significant correlation between the participants' body weight and $\mathrm{VO}_{2}$ max (Chatterjee et al. 2006).

The present findings also showed no association between the body weight and $\mathrm{VO}_{2}$ max as well as height and VO2max. This may be as a result of the age variations and interindividual differences during adolescence, because VO2max increment during adolescence could primarily be determined by changes in body weight (PaRizkova and Bunc 1987). There was an inverse statistically strong relationship between BMI and VO2max of the participants of this study. This finding is consistent with the previous findings which indicated statistically significant correlations between BMI, waist circumference, and VO2max were (Napradit and Pantaewan 2009; Setty et al. 2013; Pramadita et al. 2014; De Araujo et al. 2015).

In a cross-sectional study consisting of 2419 school teenagers aged 12 years old, living in a southern Taiwan county, it was reported that the BMI and PA were significantly associated with cardiorespiratory fitness levels (Hsieh et al. 2014). Despite this relationship, it is important to understand that a high BMI is usually associated with low aerobic capacity (De Araujo et al. 2015). Therefore, youth with a normal BMI generally possess better CRF levels than those who are underweight, overweight, or obese (Hsieh et al. 2014).

Findings from the multiple linear regression analysis showed that the independent variables (weight, height, gender, and BMI) significantly predicted $\mathrm{VO}_{2}$ max of the participants studied. Results of this model determined for BMI support the finding of Culbertson et al. (2008) which showed BMI to be a significant predictor of $\mathrm{VO}_{2}$ max in the United States. Furthermore, previous studies have also found BMI to be a greater predictor of $\mathrm{VO}_{2}$ max , particularly in women (Culbertson et al. 2008; Dagan et al. 2013). Spartali et al. (2014) also reported that BMI is a predictor of physical performance in terms of $\mathrm{VO}_{2}$ max among 868 male Hellenic Army Academy cadet with an average age of $19.9 \pm 1.6$ years in Greece. 
Gender was found to be a predictor of $\mathrm{VO}_{2}$ max in the current study. This finding mimics that of Santos et al. (2011) in which age and gender were significant predictors of $\mathrm{VO}_{2} \mathrm{max}$. In the study of Vehrs et al. (2007) where gender, age, body mass, steady-state heart rate, and jogging speed $(\mathrm{mph})$ were included as independent variables in a multiple linear regression model, to predict $\mathrm{VO}_{2} \mathrm{max}$, it was found that gender was a significant predictor of $\mathrm{VO}_{2}$ max . Furthermore, the researchers' findings also showed that body weight (Chatterjee et al. 2006; Vehrset al. 2007), and height (Chatterjee et al. 2006) were significant predictors of $\mathrm{VO}_{2}$ max among the studied sample.

\section{Conclusion}

From this present study, it could be concluded that body weight, height, gender, and BMI are good predictors of CFR in school-going adolescents. Additionally, among other predictor variables, height was found to be the highest predictor of CFR.

\section{Recommendations}

Based on the findings of this study, the equation established is suggested as dependable, usable, and appropriate to predict VO max in the Nigerian sample studied. Future studies on Nigerian children should cross-validate the prediction equation proposed in this study in order to confirm its accuracy and applicability in similar contexts.

\section{Acknowledgement}

The authors acknowledge the participants of this study, and the assistance of the final year students of the Department of Physical and Health Education, Obafemi Awolowo University, Ile-Ife, Nigeria in the collection of data. 


\section{References}

Anderssen SA, Cooper AR, Riddoch C, Sardinha LB, Harro M, Brage S, Andersen LB 2007. Low cardiorespiratory fitness is a strong predictor for clustering of cardiovascular disease risk factors in children independent of country, age and sex. Eur J Cardiovasc Prev Rehabil, 14: 526-531.

Andreasi V, Michelin E, Rinaldi AE, Burini RC 2010. Physical fitness and associations with anthropometric measurements in 7 to 15 -year-old school children. Jornal de Pediatria, 86: 497-502.

Bray M, Hagberg J, Perusse L, Rankinen T, Roth S, Wolfarth B, Bouchard C 2009. The human gene map for performance and health-related fitness phenotypes: The 2006-2007 update. Med Sci Sports Exerc, 41: 35.

Camhi SM, Katzmarzyk PT 2010. Tracking of cardiometabolic risk factor clustering from childhood to adulthood. Int $J$ Pediatr Obes, 5: 122-129.

Chatterjee SA, Chaterjee P, Bandyopadhyay A 2006. Prediction of maximal oxygen consumption from body mass, height and body surface area in young sedentary subjects. Indian J Physiol Pharmacol, 50: 181-186.

Cooper KH 1968. A means of assessing maximal oxygen intake: Correlation between field and treadmill testing. JAMA, 203: 201-204.

Culbertson J, Byars A, Keith S, Greenwood M 2008. Relationship of various body composition parameters used for predicting $\mathrm{VO}_{2} \max$. J Int Soc Sports Nutr, 5: 1.

Dagan SS, Segev S, Novikov I, Dankner R 2013. Waist circumference vs body mass index in association with cardiorespiratory fitness in healthy men and women: a cross sectional analysis of 403 subjects. Nutr $J, 12: 1$.

Dancey C, Reidy J 2004. Statistics without Maths for Psychology: Using SPSS for Windows. London, UK: Prentice Hall.

De Araujo SS, Miguel-dos-Santos R, Silva RJ, Cabral-de-Oliveira AC 2015. Association between body mass index and cardiorespiratory fitness as predictor of health status in schoolchildren. Revista Andaluza de Medicina del Deporte, 8: 73-78.

Demirkan E, Can S, Arslan E 2016. The relationship between body composition and aerobic fitness in boys and girls distance runners. Int J Sports Sc, 6: 62-65.

Esmaeilzadeh S, Kalantari H, Nakhostin-Roohi B 2013. Cardiorespiratory fitness, activity level, health-related anthropometric variables, sedentary behaviour and socio-economic status in a sample of Iranian 7- 11 year old boys. Biol Sport, 30: 67-71.

Gonçalves R, Szmuchrowski LA, Prado LS, Couto BP, Machado JC, Damasceno VO, Lamounier JA 2015. Selected anthropometric variables and aerobic fitness as predictors of cardiovascular disease risk in children. Biol Sport, 32: 255-260.

Heroux M, Onywera V, Tremblay MS, Adamo KB, Lopez Taylor J, Jáuregui Ulloa E, Janssen I 2013. The relation between aerobic fitness, muscular fitness, and obesity in children from three countries at different stages of the physical activity transition. ISRN Obesity, Article ID 134835, 10 pages.

Hsieh PL, Chen ML, Huang CM, Chen WC, Li CH, Chang LC 2014. Physical activity, body mass index, and cardiorespiratory fitness among school children in Taiwan: A cross-sectional study. Int $J$ Environ Res Publ Health, 11: 7275-7285.

LaMonte MJ, Barlow CE, Jurca R, Kampert JB, Church TS, Blair SN 2005. Cardiorespiratory fitness is inversely associated with the incidence of metabolic syndrome a prospective study of men and women. Circulation, 112: 505-512.

Lohman TG 1987. The use of skinfold to estimate body fatness on children and youth. $J$ Phys Educ Recreat Dance, 58: 98-103. 
Marfell-Jones MJ, Olds T, Stewart AD, Carter L 2006. International Standards for Anthropometric Assessment. Australia: The International Society for the Advancement of Kinanthropometry.

Minasian V, Marandi SM, Kelishadi R, Abolhassani H 2014. Correlation between aerobic fitness and body composition in middle school students. Int $J$ Prev Med, 5: S102.

Monyeki MA, Neetens R, Moss SJ, Twisk J 2012. The relationship between body composition and physical fitness in 14 year old adolescents residing within the Tlokwe local municipality, South Africa: The PAHL study. BMC Public Health, 12: 1 .

Napradit P, Pantaewan P 2009. Physical fitness and anthropometric characteristics of royal Thai army personnel. $J$ Med Assoc Thai, 92: S16-S21.

Ostojic SM, Stojanovic MD, Stojanovic V, Maric J, Njaradi N 2011. Correlation between fitness and fatness in 6-14-year old Serbian school children. $J$ Health Popul Nutr, 1: 53-60.

PaRizkova J, Bunc V 1987. Relationships between body dimensions and resting and working oxygen consumption in boys aged 11 to 18 years. Eur J Appl Physiol, 56: 725-736.

Pate RR, Wang CY, Dowda M, Farrell SW, O’Neill JR 2006. Cardiorespiratory fitness levels among US youth 12 to 19 years of age: findings from the 1999-2002 National Health and Nutrition Examination Survey. Arch Pediatr Adolesc Med, 160: 1005-1012.

Polit DF, Beck CT 2004. Nursing Research: Principles and Methods. Philadelphia, PA: Lippincott Williams and Wilkins.

Pramadita D, Anggunadi A, Zein MI, Hage SB, Darmidy V 2014. Body mass index and VO2 max relationship of FKUI fitness challenge 2012 participants in Gelora Bung Karno Jakarta. Int J Exerc Sci Conference Proceedings, 10: 47.

Rutenfranz J, Máèek M, Andersen KL, Bell RD, Vavra J, Radvanský J, Klimmer F, Kylian H 1990. The relationship between changing body height and growth related changes in maximal aerobic power. Eur J Appl Physiol, 60: 282-287.

Santos DA, Silva AM, Santa-Clara H, Matias CN, Fields DA, Sardinha LB 2011. Determinant factors of cardiorespiratory fitness in Portuguese adolescents of different ethnicities. Rev Bras Cineantropom Desempenho Hum, 13: 243-249.

Setty P, Padmanabha BV, Doddamani BR 2013. Correlation between obesity and cardio respiratory fitness. Int $J$ Med Sci Public Health, 2: 300-304.

Spartali I, Kostantinos H, Ioannis K, Thrasivoulos P 2014. Body fat percentage and body mass index as predictors of cadets' physical performance. Open Sports Sci $J, 7: 53-59$.

Tanha T, Wollmer P, Fedorowski A, Thorsson O, Karlsson MK, Dencker M 2016. Correlation between physical activity, aerobic fitness and body fat against autonomic function profile in children. Clin Auton Res, 26: 197-203.

Vehrs PR, George JD, Fellingham GW, Plowman SA, Dustman-Allen K 2007. Submaximal treadmill exercise test to predict VO2max in fit adults. Meas Phys Educ Exerc Sci, 11: 61-72.

Victo ER, Ferrari GL, Silva Junior JP, Araújo TL, Matsudo VK 2017. Lifestyle indicators and cardiorespiratory fitness in adolescents. Revista Paulista de Pediatria, 35: 61-68.

WHO EC 2004. Appropriate body-mass index for Asian populations and its implications for policy and intervention strategies. Lancet, 363: 157-163. 
Woll A, Kurth BM, Opper E, Worth A, Bös K 2011. The 'Motorik-Modul' (MoMo): Physical fitness and physical activity in German children and adolescents. Eur $J$ Pediatr, 170: 1129-1142.

Yorkin M, Spaccarotella K, Martin-Biggers J, Quick V, Byrd-Bredbenner C 2013. Accuracy and consistency of weights provided by home bathroom scales. BMC Public Health, 13: $1-5$. 